\title{
Viewing the development of nanomedicine in Mexico
}

\author{
Eduardo Robles-Belmont', Rebeca de Gortari-Rabiela², Pilar Galarza-Barrios', \\ Jesús Mario Siqueiros-García ${ }^{1}$ and Alejandro Arnulfo Ruiz-León ${ }^{1}$ \\ ${ }^{1}$ Institute of Research in Applied Mathematics and Systems, Laboratory of Networks; ${ }^{2}$ Institute of Social Research, Universidad Nacional Autónoma \\ de México, Ciudad de México, Mexico
}

\begin{abstract}
Objective: In this article we present a set of different visualizations of Mexico's nanomedicine scientific production data. Method: Visualizations were developed using different methodologies for data analysis and visualization such as social network analysis, geography of science maps, and complex network communities analysis. Results: Results are a multi-dimensional overview of the evolution of nanomedicine in Mexico. Moreover, visualizations allowed to identify trends and patterns of collaboration at the national and international level. Trends are also found in the knowledge structure of themes and disciplines. Finally, we identified the scientific communities in Mexico that are responsible for the new knowledge production in this emergent field of science.
\end{abstract}

KEY WORDS: Nanomedicine. Data visualization. Emerging technologies. Mexico.

\section{Introduction}

Throughout the progression of new sciences and technologies (S\&T), the discourse that promotes their advance is mainly based on potential applications. In the case of nanoscience and nanotechnologies (NCT) emergence, the discourse has focused on their potentialities in technical, economic and social terms in practically all sectors. Nanotechnologies' proposed applications are based on new physical, chemical and electrical properties of materials at nanometric scale (thousand millionth part of a meter, $10^{-9}$ ). Nanotechnologies are regarded as a window of opportunity to promote industrial growth and to answer to certain social and environmental needs. This has drawn the attention of diverse stakeholders stemming from government institutions and from the industry, as well as other social stakeholders. The promotion of nanotechnologies has been supported in some countries through national initiatives for the funding and scientific and technological research orientation towards sectors regarded as strategic.
In the health sector, nanotechnologies have found various applications ranging from drugs to prosthesis and diagnostic devices. In scientific diffusion media, applications in diagnosis and therapies for cancer and other diseases considered to be public health problems have been covered. In Mexico, the development of NCT started in the decade of 1990 and health sector institutions have participated ${ }^{1}$. In addition, other studies have demonstrated that other research groups develop new knowledge on different subareas of nanomedicine ${ }^{2}$, and the scientific networks in this field reflect collaborations with countries that have led the development of these new technologies ${ }^{3}$.

On the other hand, in the face of the emergence of new S\&T, having indicators about their progression and tendencies is necessary, both for the support of policies on S\&T and for their study from the perspective of social sciences. The subject of indicators for emergent S\&T is not new. There are research groups that develop methodological proposals for the mapping of the emergence, of the interdisciplinary nature, of available capabilities, of academic discussion, of
Date of reception: 20-12-2016

Date of acceptance: 30-12-2016

DOI://dx.doi.org/10.24875/GMM.M18000095
Gac Med Mex. 2017;153:794-803

Contents available at PubMed www.gacetamedicademexico.com 
scientific collaboration relations and of social aspects and implications.

Bibliometrics and scientometrics are two disciplines dedicated to the study and assessment of scientific production. By measuring the diversity of publications, indicators and theoretical approaches on S\&T functioning have been generated. There is a wide array of academic literature about the contributions of these disciplines ${ }^{4,5}$. The production of indicators has also been the duty of government and international agencies, whose goals are scientific and technological development policies and management. The interest of these institutional stakeholders on indicators has been focused on the formulation of recommendations for S\&T policies ${ }^{6-8}$. In addition, the indicators are used for the assessment of productivity and academic activity performance of institutions, groups and investigators. Closely related to the aforementioned uses, the indicators are also used in prospective and emerging technology studies with the purpose to identify capabilities and necessities in order to approach windows of opportunity in the emergence of new technologies.

In this context, the advances in information and communication sciences have represented important contributions. In particular, the development of Internet and the web, as well as social networks, have put large amounts of information and data that are relevant to the study of S\&T within reach for research. The academic and technologic setting has generated its own tools in the context of social networks; although services such as Twitter are widely used to diffuse, share and comment a multiplicity of subjects associated with science, there are other media that have been specifically designed for S\&T. some examples are Mendeley, Github and Figshare. The first one is focused on sharing and managing bibliographic material, especially articles; the second one is a version control system, repository and collaborative platform for the development of software of all sorts, but it is widely used for scientific calculation; and the third one is a repository for access to research-generated data. The potential that represents the access to web-generated information only has sense because, currently, there is the computational power and tools available for its analysis and visualization. Finally, the bet with these technologies is on that indicators can be developed that inform on the processes and dynamics of knowledge generation and socialization in a lapse of hours and days, in a massive form. In other words, unlike bibliometrics and scientometrics spatial and temporal scales, these technologies allow observing the process of science at a very broad spatial scale and very short temporal scale.

Information graphic representation for visualization is a common activity in most scientific disciplines. However, the use of graphic representations in combination with informatics technology to obtain an adequate visualization is relatively new. The previously mentioned advances in information and computing sciences have led to the development of visual computational tools that include hardware, software, visual interface tools for graphics and techniques, as well as data processing. As a result of the problem posed by the large volume of data that was available (the dilemma of information with no interpretation), since the middle of the decade of 1980, at the initiative of the USA National Science Foundation, developing such technology was proposed, which in addition implicated the collection, organization, modelling and representation ${ }^{9}$. Ever since, there have been great advances, since it has acquired importance in different disciplines for understanding of the processes and their complex relations. The forms in which scientific visibility can be measured and represented have been gradually transforming from indicators arranged in tables and graphs, which contain information, ideas, etc., to a representation by means of network maps, where information can turn into a knowledge base. Social network visualization can be an important tool for explaining data, since it helps the investigator to screen them, detect patters of interest and give sense to observations ${ }^{10}$. In addition, it enables the understanding of entire data structures and of the relations between different elements, as well as the formulation of hypotheses that can become the subject of analysis $^{11}$. The analysis of relational data about scientific production can provide knowledge that enables complementing the bibliometric and scientometric analysis with social network analysis and other data analyses. In the face of these new tools for data analysis, the question arises on what their contribution is for the production of S\&T indicators in emerging fields. Other issues we are interested in are the specialization areas and their role in collaboration, which institutions are behind and what role do promotion and collaboration policies, just to mention a few, play in the networks.

Building on both these bases, the emergence of nanomedicine and the visualization of data for mew S\&T data, in this article we present the results of a study on the production of new scientific and 
technologic knowledge in the field of nanomedicine in Mexico until the year 2014. Other works have already analyzed the emergence and development nanomedicine in Mexico ${ }^{2,3,12}$, the results of which provide a broad panorama of this emerging field in the country. In the present study, the results are presented in the form of diverse visualizations of different bibliometric data about areas of nanomedicine and its relationships, the spatial dimension of scientific collaborations in this emerging technology, institutional collaborations, the disciplines involved and the mapping of scientific communities. The visualizations presented in this work complement other studies conducted on the development of nanomedicine in Mexico.

\section{Methods}

This study is based on the use of bibliometric and scientometric tools to analyze data about scientific publications published in Mexico in the field of nanomedicine, produced in Mexico and indexed in Web of Science. The identification of bibliographic references has been carried out based on the search strategy proposed by Wagner et al..$^{13}$, which has been replicated for the study of the emergence of nanomedicine in Latin America and the Caribbean ${ }^{2}$, and uses several key words that are representative of seven areas concerning human health drug administration; drugs and therapy; in vivo imaging; biosensors and biomaterials; intelligent implants/neuronal prostheses; and the search strategy was added the term "Nanomedicine" with the purpose to identify academic works that address the subject with a general perspective and from the perspective of other disciplines of social sciences. In addition, the cosmetics area was eliminated, since we don't consider it to be an area in the health sector with important implications on its needs.

On the other hand, let's remember that the purpose of this study is to present indicators through visualizations of data. Avoiding the use of tables and histograms to describe the indicators is attempted. These tools help us to generate visualizations of the data based on their relational analysis. The presented results are multilevel, since we describe a) international collaborations, b) institutional collaboration networks, and c) scientific collaborations of different investigators. In addition, the visualizations reflect the areas or disciplines of knowledge where new knowledge produced in the field of knowledge in Mexico has been published. As a whole, these results are known as maps of science ${ }^{14,15}$, and visualizing them from the perspective of the disciplines present in the development of new knowledge can reveal the relationships between different disciplines in the production and accumulation of new knowledge. Furthermore, this type of visualizations can provide us with clues of the dynamics in the processes of convergence of knowledge in emergent fields.

The visualizations were made based on different softwares and technologies that allow for geographic maps to be obtained, as well as social networks and cluster analyses and their comparison throughout time. The social networks analyses have been performed mainly with the Pajek program. The international collaboration map has been based in the methodology proposed by Leydesdorff and Persson ${ }^{16}$. The analyses and visualizations of communities have been carried out with the Map Equation methodology ${ }^{17}$. The references to these tools and methodologies will be specified in the results sections.

\section{Results}

\section{Development of the nanomedicine areas in Mexico}

Until the year 2014, 265 articles have been produced in the field of nanomedicine in Mexico. The first articles were published by the end of the decade of 1990. However, it is from the year 2006 on when the production exceeds 10 annual articles, and the growth in article production has considerably increase since $2010^{*}$. This shows that the field of nanomedicine is still at early stages of its emergence.

The first visualization is about the distribution of these articles in five of the six mapped nanomedicine areas, in addition to the area denominated nanomedicine. In figure 1, a network is shown where each node represents the six identified areas; their size is determined by the number of articles in each area, and the lines represent the relations between the areas, based on the distribution of articles in more than one area. This network has been generated with Pajek and visualized with VOSviewer ${ }^{18}$. In this visualization we appreciate that the most developed area concerns to

\footnotetext{
* In this work we don't present a growth chart of articles produced in Mexico in the field of nanomedicine, since the purpose is to explore new data visualizations other than the common ones, such as histograms. The reader can consult other works where scientific production evolution in this field has been analyzed2,3,12.
} 


\section{Drug administration $(49.43 \%)$}

Figure 1. Nanomedicine thematic areas developed in Mexico until 2014 (source Web of Science, Thomson Reuters, February 2016; own creation and visualization with VOSviewer).

drug administration, with practically $50 \%$ of articles. As a matter of fact, this area is one of the most developed in nanomedicine in the entire world, with its scientific investigations being oriented to the development of targeted drug administration, toxic effect reduction, safety and biocompatibility, as well as to rapid development of safe medications ${ }^{19}$.

In vivo imaging is the second area in nanomedicine in Mexico, and it represents $28.3 \%$ of scientific production. Imaging has found a boom with nanotechnology in the development of diverse investigations around diagnosis and therapies for cancer. Indeed, different projects have focused on nanoparticles new properties (e.g., magnetic, electronic and optical properties) for different applications to in vivo imaging ${ }^{20}$.

The two following areas are biomaterials (10.57\%) and biosensors (8.30\%). Biomaterials have raised growing interest for application in medicine when combined with nanomaterials new properties; it is about the development of tissue substitutes, biosensors and diagnostic systems, as well as drug controlled delivery ${ }^{21}$. Research in this area has also focused on addressing different obstacles found in the use of nanomaterials ${ }^{22}$. The areas with lower production are those of drugs and therapy (2.64\%), a result that draws our attention, since the pharmaceutics sector is where the main promises of advance with nanomedicine have arisen, and in the case of Mexico, it is one of the two less developed areas.
Figure 1 also shows the relationships between the areas identified in the field of nanomedicine based on the approach proposed by Wagner et al. ${ }^{13}$. This nanomedicine map shows that all areas are related to drug administration, which is the most developed area in Mexico. That is, completed and ongoing research works are identified that are transverse to the drug administration area and to each one of the other identified areas. This same map shows the presence of investigations that are transverse to the areas of biomaterials, biosensors and drug administration, which reflects that in the lines of research that are developed in Mexico there is also concern around the obstacles in the use of nanomaterials in drugs. This could be related, on one hand, to the lack of toxicity studies, and on the other, to the absence of rules and regulations.

\section{Scientific collaborations}

The second visualization we are interested in reviewing concerns international scientific collaborations. This visualization is based on the analysis of collaboration networks, and the methodology builds on the work by Leydesdorff and Persson ${ }^{16}$ for the creation of geographic maps for science. Figure 2 shows the geographic map for international collaborations in the development of nanomedicine in Mexico. The data to construct this visualization have been the 


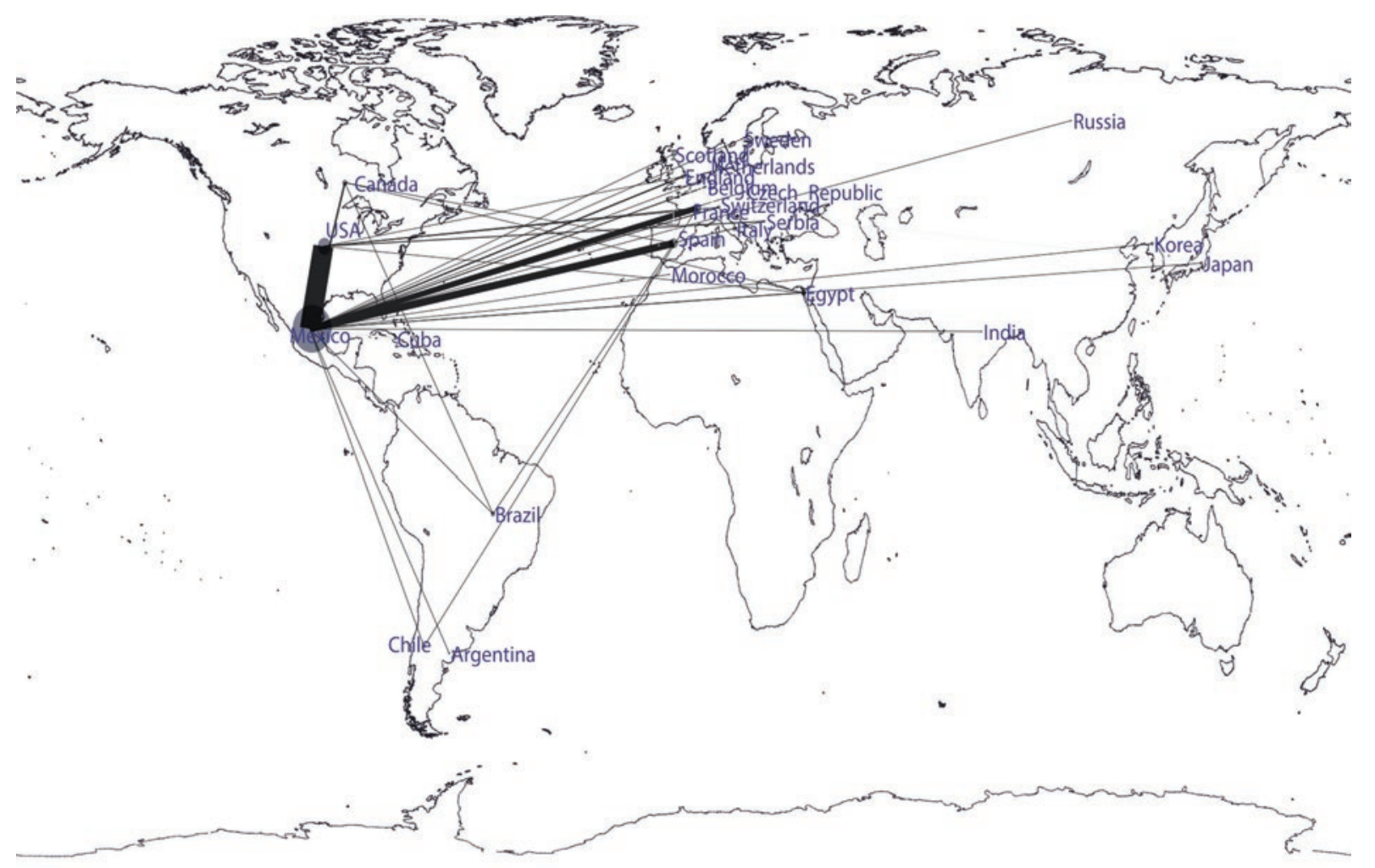

a.

Figure 2. International collaborations in the development of nanomedicine in Mexico until 2014 (source: own creation with Web of Science data).

co-authorships of investigators assigned to institutions in Mexico with their peers assigned to foreign institutions. It draws our attention the low number of international collaborations by Mexican research groups in this field. Out of 265 article published until 2014, only 61 have been produced in international collaboration. Although there are few collaborations, the trends they show are similar to those observed in other sectors of nanotechnology or other emerging technologies. In this first visualization, the main collaborations are shown to have been maintained with USA investigators. Then, collaborations with European countries stand out. However, collaborations with countries of the Latin America and Caribbean region are little significant. Such results may be due to the fact that Mexican researchers have been trained mainly in the USA and Europe.

On the other hand, the visualization in figure 3 focuses on both national and international institutional scientific collaborations in nanomedicine in Mexico. The central part of the image shows the Mexican educational and research institutions. The National Autonomous University of Mexico (UNAM - Universidad Nacional Autónoma de México), the Institute of Research and Advanced Studies and the National
Polytechnic Institute are the institutions with the highest presence in the development of nanomedicine in the country. This confirms a concentration of capacity and activities in these three Mexican entities. In spite of this concentration of capabilities, it is interesting for the distribution of the other institutions present in the development of nanomedicine to be highlighted. On one hand, the Public Research Centers of the National Council of Science and Technology (CONACYT Consejo Nacional de Ciencia y Tecnologia), initially formed mainly by nuclei of UNAM-graduate investigators, who have managed to contribute with knowledge in different regions. On the other hand, and as a result of changes in the S\&T policies, the most important public universities have been able to produce important advances in these emergent fields. Finally, the presence of federal health institutions and laboratories that participate in this development, and whose creation and growth have been mainly based on the funding received from government sources, also stands out.

On the other hand, figure 3 also reveals a quite broad distribution of international scientific collaborations. This draws our attention, since it involves 61 collaborations that are very recent, which date from 


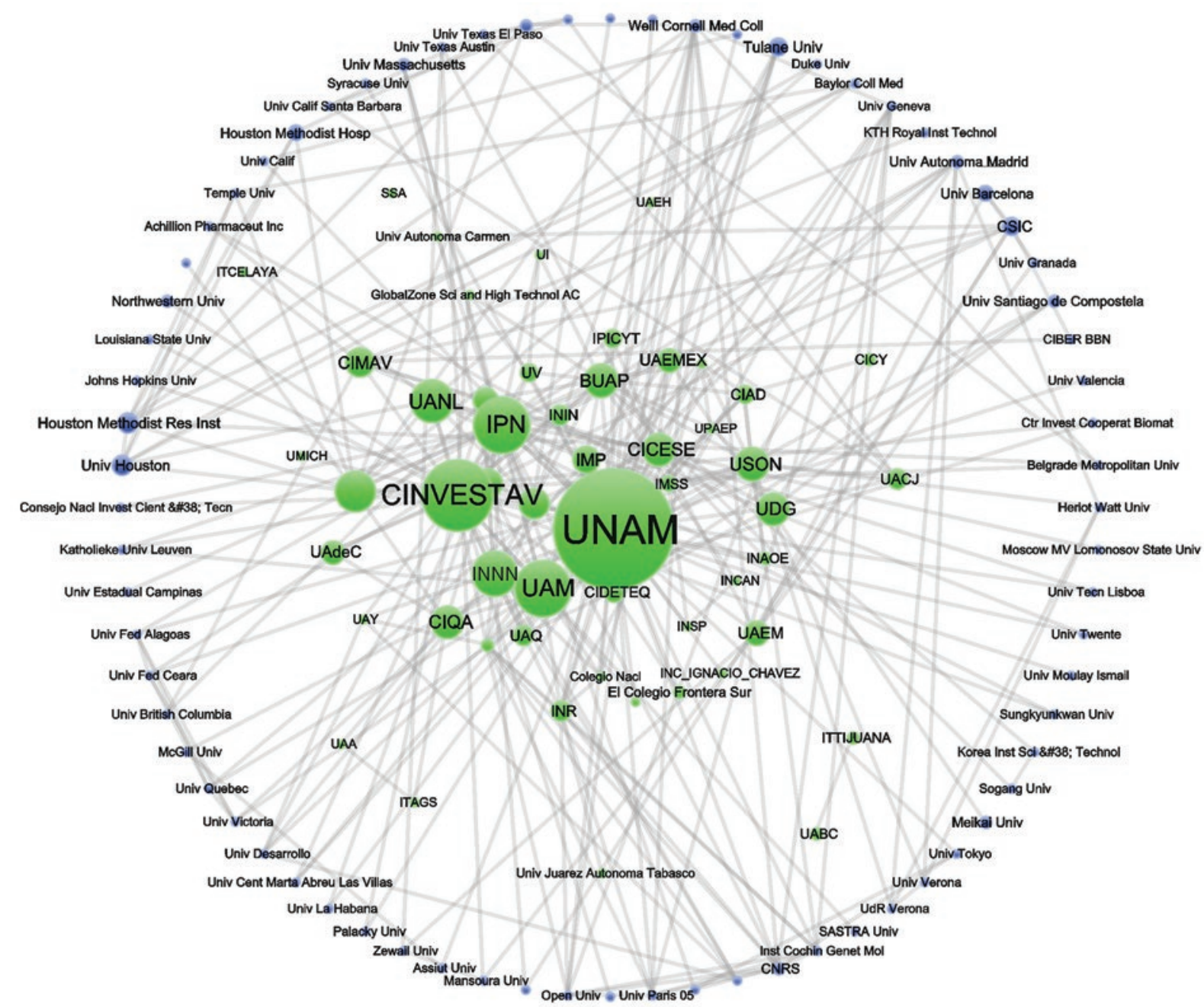

Figure 3. Distribution of national and international scientific collaborations in the field of nanomedicine in Mexico until 2014 (source: own creation with Web of Science data).

2012 on, and can be interpreted as a characteristic of recent internationalization of science in nanomedicine. In this regard, it should be pointed out that the development of NCT has occurred in the middle of a context of internationalization and commercialization of science ${ }^{23-25}$. Additionally, in these new scientific and technological knowledge production, use and dissemination dynamics, in general, it could be said that there is a modification of public policies, where one of the mainstays is knowledge economics, in such a way that science, technology and innovation is trying to be oriented towards competitiveness and productive chains. In the case of emerging technologies, such as NCT, although there is no national initiative with clear goals, research in these fields not only has increased, but is has diversified, leaning on its multidisciplinary nature ${ }^{26}$. In addition, these collaboration networks have benefited from knowledge and capabilities transference based on mobility relationships with investigators from other countries, thus showing that international mobility enables the creation of networks based on access to infrastructure and new technologies. Finally, we consider that the set of institutional and international programs of support to the development of these emerging technologies, as well as the training of human resources, have contributed to the recent growth of these collaborations.

\section{Areas of knowledge}

Another interesting indicator to be visualized concerns disciplines and areas of knowledge that contribute to emerging S\&T. In this section, we are interested in reviewing another perspective of visualization based on the disciplines of knowledge, as well as 


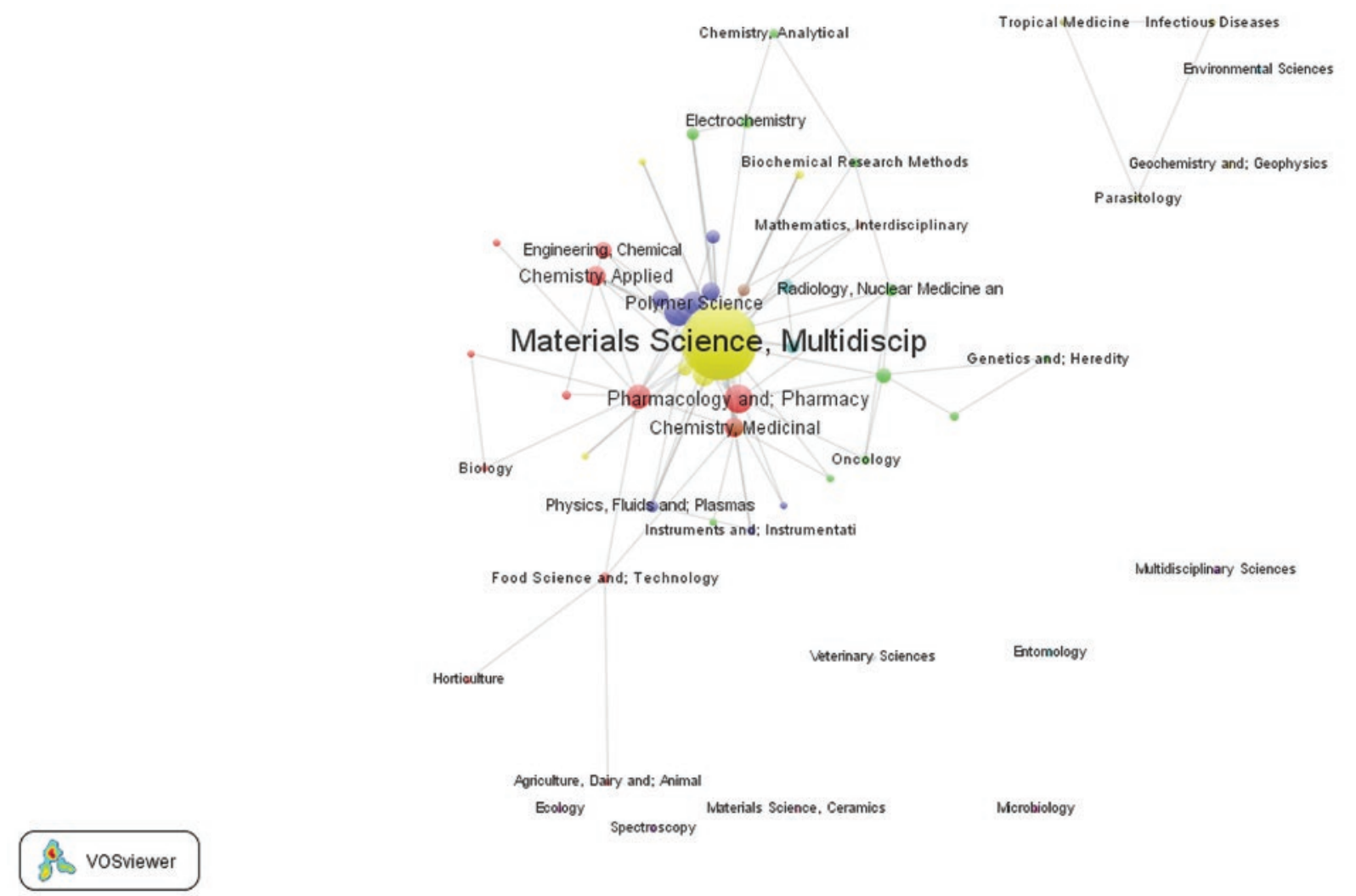

Figure 4. Map of the areas of knowledge present in the development of nanomedicine in Mexico until 2014 (source: own creation with Web of Science data).

their relationships in the production of new knowledge. The results of these visualization techniques are known as maps of science ${ }^{14,15}$, and the input data are the categories where the scientific journals where the scientific articles have been published are indexed.

Figure 4 shows the map of areas of knowledge based on the categories of the Web of Science classification. The Web of Science network has been generated with Pajek and analyzed with the Louvain ${ }^{27}$ method for identification of communities, and the visualization with VOSviewer developed by Waltman and Van Eck ${ }^{18}$. Sixty Web of Science citations were identified where the scientific journals of our sample are classified (265 articles), and the Louvain classification of communities' analytic method, based on modularity optimization ${ }^{27}$. This analysis yielded a total of 15 clusters. These results are shown in figure 4, where the size of the node is determined by the frequency of Web of Science entries, which indicates that science of materials is the main discipline in the development of nanomedicine in Mexico. Other basic science disciplines present in this map are related to the area of chemistry, and to a lesser extent, the presence of other disciplines such as pharmacology and pharmacy, as well as other disciplines of medical sciences, is appreciated. We find it interesting to evoke that centrality in science of materials, in the Mexican case, might be explained by the fact that NCT have been developed in departments, laboratories and centers with a tradition in this area. This drives us to classify it as the convergent thematic area in the development of nanomedicine, i.e. the area where more sources are shared by other areas, and the one that contributes with more knowledge to the rest.

The visualization shown in figure 4 is interesting, since it shows a picture of the structure of knowledge in the development of nanomedicine in Mexico. However, one limitation of this type of visualizations is that it doesn't allow showing the dynamics in the development of this emerging problem. It is, indeed, a static image of the structure of knowledge in nanomedicine. Therefore, in order to show a dynamic visualization that enables observing the development of the presence of disciplines in the field of nanomedicine in Mexico over time, we have used the tool to generate comparisons in social networks time proposed by 


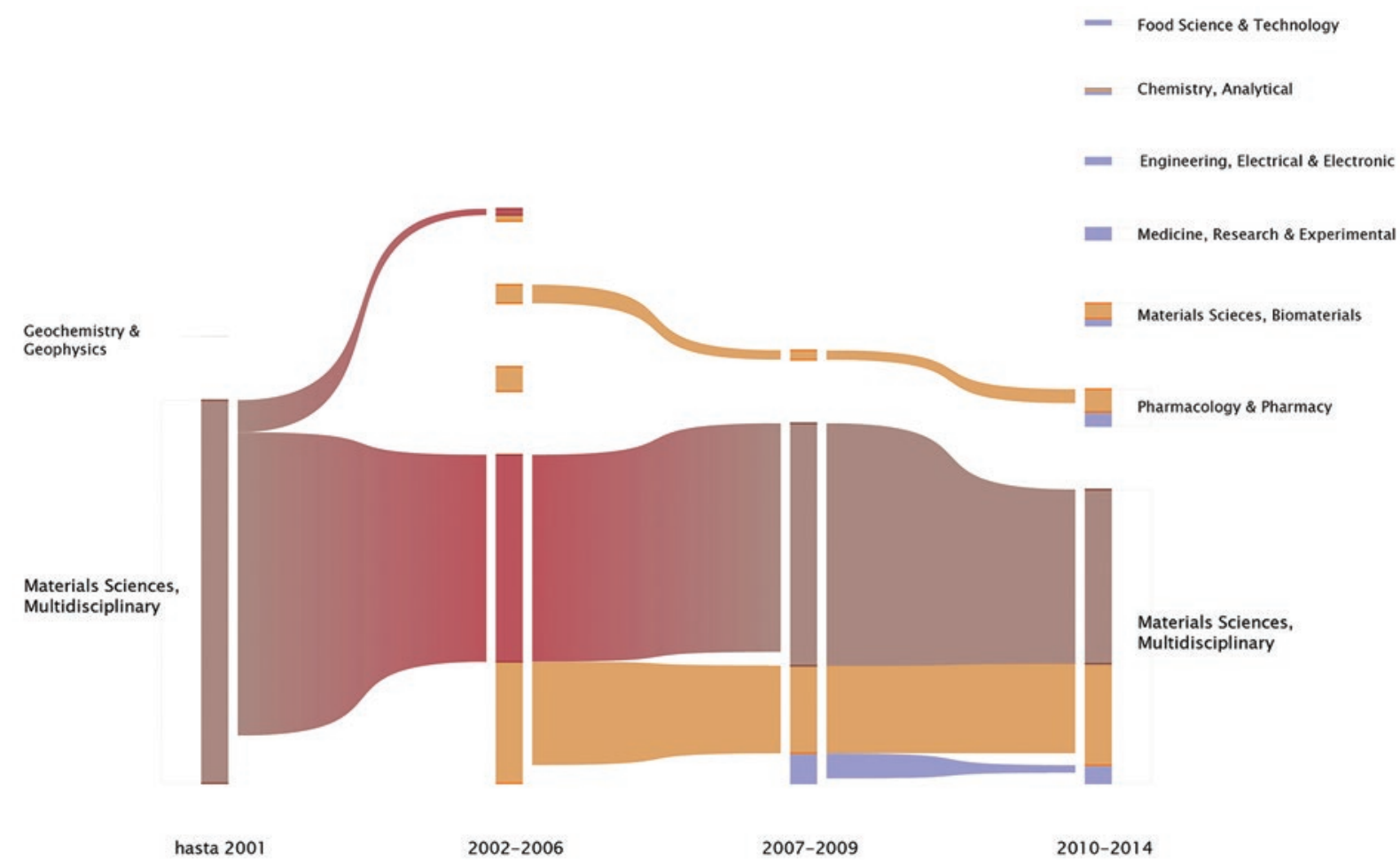

Figure 5. Development of the structure of knowledge in nanomedicine in Mexico until 2014 (source: own creation with Web of Science data).

Rosvall and Bergstrom ${ }^{28}$. We have divided the data in four periods, the cutoff points of which have been established according to the dates regarded as having marked the development of NCT in Mexico**.

Figure 5 shows the result of this visualization, which enables observing the profile change of knowledge in nanotechnology in Mexico over time. This result confirms material sciences central presence and evolution in the analyzed period, where we see how it has contributed to other areas of knowledge in nanomedicine. If we complement this visualization's interpretation with figure 4 , we can observe that this area of knowledge is related to physics, to polymer sciences and to chemistry. On the other hand, the results show that the emergence of nanomedicine in the area of drugs was initiated from the first decade of this century on. Furthermore, discoveries in other areas of knowledge in this emerging technology have arisen after that decade.

\section{Scientific communities}

The last visualization refers to the communities of investigators that have participated in the development of the nanomedicine area in Mexico. We are interested on this exercise to identify the different communities of investigators that carry out scientific activities in different areas of nanomedicine in Mexico. This was accomplished based on the co-authorships of the 265 identified articles, with a total of 1050 Mexican and foreign authors.

This analysis of communities was carried out with the Map Equation method ${ }^{17}$, which is based on the flow of information in the structure of a network the possible partitions of which are determined by its random travelling. This analysis has yielded a total of 25 communities (Fig. 6). Each identified community has been labeled in the area of nanomedicine where the published articles have been characterized. The visualization of these communities shows that the majority develops new

** The first cutoff point in time is in 2001, which corresponds to the launch of the National Initiative for Nanotechnologies in the USA, established considering it as the beginning of the international race for the development of emerging technologies. The second cutoff point has been established in 2006, when the installation of important structure took place in the framework of the CONACYT National Laboratories initiative. The third cutoff point has been established in 2009, since that year were the first CONACYT Thematic Networks created, among which at least two are dedicated to the field of nanotechnologies. The last cutoff point has been established until 2014 with the purpose to have updated data and not having an indexing queue bias, which in the case of scientific documents can be reflected even up to 2 years later. 


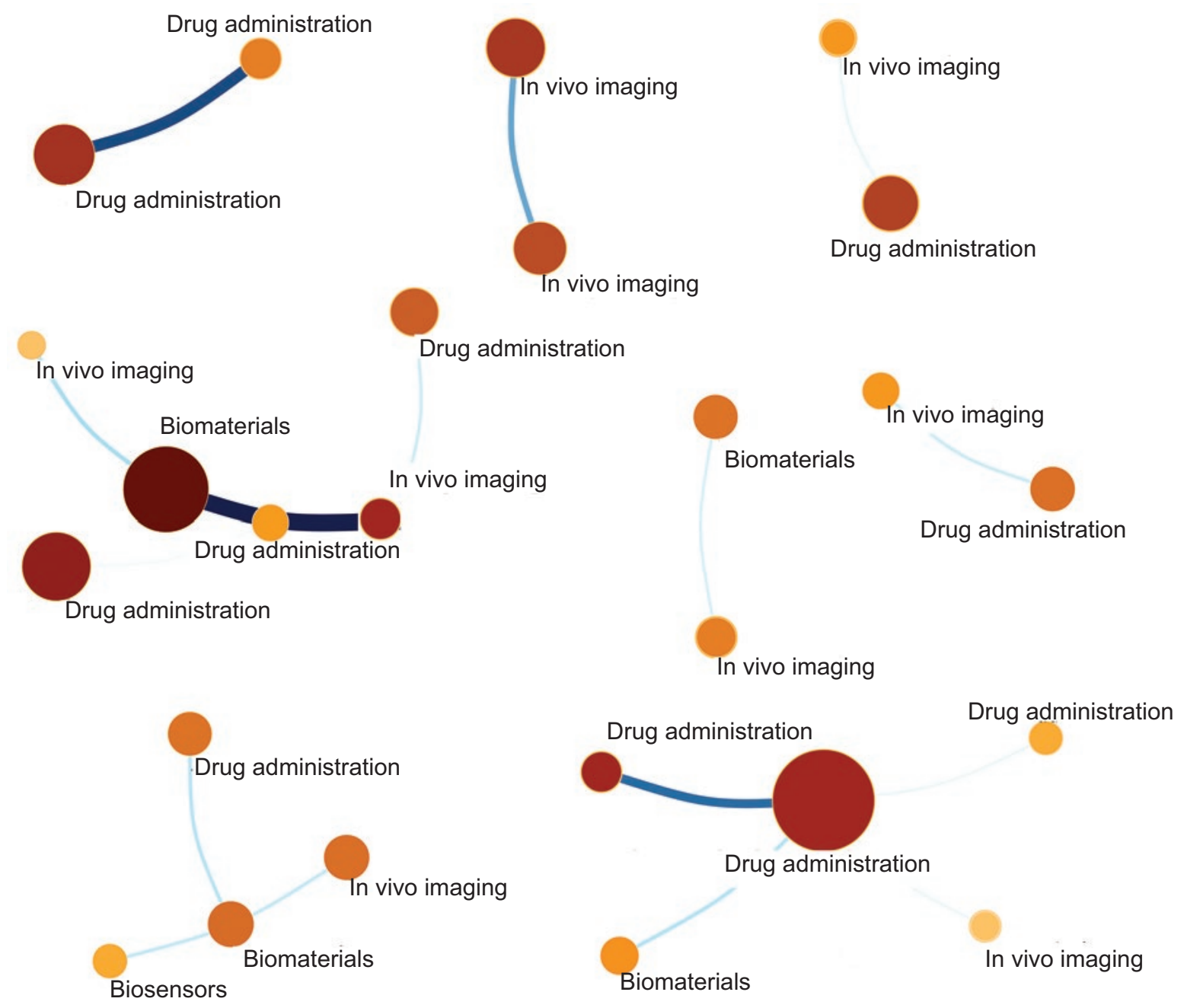

Figure 6. Scientific communities in the development of nanomedicine in Mexico until 2014 (source: own creation with Web of Science data).

knowledge in the area of drug administration (11 communities), followed by in vivo imaging. In addition to identifying the communities by nanomedicine area, with this visualization, we found it interesting for the relations between different communities to be identified. For example, in the visualization shown in figure 6, two heterogeneous groups, comprised by communities of different areas, can be appreciated the first one, where the main community is biomaterials, has also relationships through co-authorships of articles with the areas of in vivo imaging and drug administration, and in the second group, the main community works in drug administration and has maintained collaborative relations with the areas of biomaterials and in vivo imaging.

\section{Conclusions}

In this work, we have established that the new tools for data visualization are interesting for studies on the their application for technological monitoring and surveillance, as well as for mapping in science and technology social studies, and allows for trends, relationships, strengths and weaknesses, as well as for the main institutional and scientific stakeholders to be identified. Furthermore, data visualization with these new tools enable obtaining new representations of scientific and technological systems from different inputs and perspectives, thus potentiating science and technology interpretative and analytical capabilities. However, the use of these tools should be carefully taken. Each tool has particular characteristics that limit its use for different cases. Knowledge and use of diverse data visualization tools allows for certain limits to be surpassed, which renders the tools being complementary to each other. Each one of the visualizations constructed from different inputs nourishes the task of mapping a scientific task. On the other hand, it should be mentioned that the methodologies and tools employed in this study are freely accessible, 
which opens the possibility for these visualizations to be reproduced in other studies.

With regard to the development of nanomedicine in Mexico, geographically-visualized international collaboration networks provide a broad perspective about the geographic distribution of scientific collaboration relationships of this emerging field. The results show international collaboration growing dynamics, which indicates that new S\&T have accelerated internationalization processes. These processes may be due to different factors, such as scientific visibility, institutional collaboration agreements and development of subjects in common, among others. It is also interesting pointing out that, when the analysis was performed at different levels, a broad institutional and at the same time concentrated distribution in the USA and some European countries was found. This collaboration configuration raises various questions around the dynamics of the development of new S\&T and the role of North-South relationships, a subject that is beyond the scope of this study, but that is important mentioning.

In addition, the analysis of the structure of this emerging field has shown, on one hand, the importance of the sciences of materials and other disciplines of physics and chemistry since the first publications. Bringing this analysis of the nanomedicine structure to another level has shown that the development of drugs in Mexico has been central. Finally, the analysis of this structure in time has shown an interesting visualization of the development of nanomedicine and on how new scientific knowledge has permeated in different scientific disciplines. However, the absence of the private sector in the development of scientific knowledge in nanomedicine in Mexico suggests that the developed knowledge is still basic.

\section{Acknowledgements}

This research was supported by the IA300916 project of UNAM Programa de Apoyo a Proyectos de Investigación e Innovación Tecnológica (PAPIIT).

\section{References}

1. Robles-Belmont E, Vinck D. A panorama of nanoscience developments in Mexico based on the comparison and crossing of nanoscience monitoring methods. J Nanosci Nanotechnol. 2011;11:5499-507.
2. Invernizzi N, Foladori G, Robles-Belmont E, et al. Nanotechnology for social needs: contributions from Latin American research in the areas of health, energy and water. J Nanoparticle Res. 2015;17:233.

3. Robles-Belmont E. Cooperación científica internacional en la nanomedicina de México. Obs Desarro. 2014;3:29-33.

4. Pritchard A. Statistical bibliography or bibliometrics? J Doc. 1969;25:348-9.

5. Garfield E. Citation indexing: its theory and applications in science, technology and the humanities. New York: John Wiley \& Sons; 1979. 274 p.

6. OECD. Proposed standard practice for surveys on research and experimental development. Frascati Manual. Paris; 2002. Disponible en: http:// www.oecd-ilibrary.org/science-and-technology/frascati-manual-2002_9789264199040-en

7. OECD. Oslo manual. Guidelines for collecting and interpreting innovation data. $3^{\text {rd }}$ ed. Paris: OECD; 2005. 166 p. Disponible en: http://www.oecd-ilibrary.org/science-and-technology/oslo-manual_9789264013100-en

8. Jaramillo H, Lugones G, Salazar M, editores. Normalización de indicadores de innovación tecnológica en América Latina y el Caribe. Manual de Bogotá. RICYT, OEA, CYTED; 2001. 102 p. Disponible en: http:// www.uis.unesco.org/Library/Documents/Bogota Manual_Spa.pdf

9. Torres Ponpúan D. Aproximaciones a la visualización como disciplina científica. Acimed. 2009;20:161-74.

10. Brandes $U$, Kenis $P$. La explicación a través de la visualización de redes. REDES - Revista hispana para el análisis de redes sociales. 2005;9(6). Disponible en: http://revista-redes.rediris.es/html-vol9/vol9 6.htm

11. Moya-Anegón F, Vargas-Quesada B, Chinchilla-Rodríguez Z, et al. Visualización y análisis de la estructura científica española: ISI Web of science 1990-2005. Disponible en: http://www.academia.edu/1430783/ Visualizaci\%C3\%B3n_y_an\%C3\%A1lisis_de_la_estructura cient\%C3\%ADfica_espa\%C3\%B10la_ISI_Web_of_Science_1990-2005

12. Robles-Belmont, E. and de Gortari-Rabiela, R. Dynamics of the emergence of micro an nanotechnologies in the healthcare sector in Mexico. Nanotech L \& Bus. 2013; 10:54-64.

13. Wagner V, Husing B, Gaisser S, et al. Nanomedicine: drivers for development and possible impacts. European Commission Joint Research Centre. Sevilla; 2008. Disponible en: http://ftp.jrc.es/EURdoc/ JRC46744.pdf

14. Leydesdorff $L$, Rafols I. A global map of science based on the ISI subject categories. J Am Soc Inf Sci Technol. 2009;60:348-62.

15. Bornmann L, Leydesdorff L, Walch-solimena $C$, et al. Mapping excellence in the geography of science: an approach based on Scopus data. J Informetr. 2011;5:537-46.

16. Leydesdorff L, Persson O. Mapping the geography of science: distribution patterns and networks of relations among cities and institutes. J Am Soc Inf Sci Technol. 2010;61:1622-34.

17. Rosvall M, Axelsson D, Bergstrom CT. The map equation. Eur Phys J Spec Top. 2009;178:13-23.

18. Waltman L, Van Eck NJ. A new methodology for constructing a publication-level classification system of science. J Am Soc Inf Sci Technol. 2012;63:2378-92.

19. De Jong WH, Borm PJ. Drug delivery and nanoparticles: applications and hazards. Int J Nanomedicine. 2008;3:133-49.

20. Cuenca AG, Jiang $\mathrm{H}$, Hochwald $\mathrm{SN}$, et al. Emerging implications of nanotechnology on cancer diagnostics and therapeutics. Cancer. 2006;107:459-66.

21. Liu H, Webster TJ. Nanomedicine for implants: a review of studies and necessary experimental tools. Biomaterials. 2007;28:354-69.

22. Doshi N, Mitragotri S. Designer biomaterials for nanomedicine. Adv Funct Mater. 2009;19:3843-54

23. Wong PK, Ho YP, Chan CK. Internationalization and evolution of application areas of an emerging technology: the case of nanotechnology. Scientometrics. 2007;70:715-37.

24. Gómez Uranga M, Etxebarria Kerexeta G, Campàs-Velasco J. The dynamics of commercialization of scientific knowledge in biotechnology and nanotechnology. Eur Plan Stud. 2007;15:1199-214.

25. Fernández-Ribas AA, Shapira $P$. Technological diversity, scientific excellence and the location of inventive activities abroad: the case of nanotechnology. J Technol Transf. 2009;34:286-303.

26. Robles-Belmont E, De Gortari Rabiela R. NST without NII ? The Mexican case study. En: Ramani SV, editor. Nanotechnology: what's in it for emerging countries? Cambridge: Cambridge University Press; 2007. p. 182-210.

27. Blondel VD, Guillaume J-L, Lambiotte R, et al. Fast unfolding of communities in large networks. J Stat Mech Theory Exp. 2008;10008:6. Disponible en: http://arxiv.org/abs/0803.0476

28. Rosvall M, Bergstrom CT. Mapping change in large networks. PLoS One. 2010;5:e8694. 